This PDF is a selection from an out-of-print volume from the National Bureau of Economic Research

Volume Title: Medical Care Output and Productivity

Volume Author/Editor: David M. Cutler and Ernst R. Berndt, editors

Volume Publisher: University of Chicago Press

Volume ISBN: 0-226-13226-9

Volume URL: http://www.nber.org/books/cut101-1

Publication Date: January 2001

Chapter Title: The Value of Reductions in Child Injury Mortality in the United States

Chapter Author: Sherry A. Glied

Chapter URL: http://www.nber.org/chapters/c7640

Chapter pages in book: (p. 511 - 538) 


\title{
The Value of Reductions in Child Injury Mortality in the United States
}

\author{
Sherry Glied
}

One of the bright spots in the changing circumstances of American children over the past three decades has been the significant decline in child mortality. The mortality rate among children ages one through four fell 57 percent between 1960 and 1990, and the rate for children ages five through fourteen fell 48 percent over those thirty years (U.S. Department of Health and Human Services 1963, 1994). In percentage terms, these declines are steeper than those experienced by any other age group.

Many of the improvements in child health stem from revolutionary developments in medicine. Congenital anomalies of the heart, many infectious diseases, and several childhood cancers, important causes of death in 1960, no longer threaten children. Further improvements, even into the 1990 s, have come through vaccination campaigns, which have nearly eradicated several childhood infectious diseases (most recently meningitis). A growing share of the reduction in child mortality, however, stems neither from medical advances nor from immunization campaigns. Rather, the most important contributor to reductions in mortality since 1970 has been a sharp decline in the rate of child mortality from unintentional injury or accidents. Among children under five, that rate dropped from 44 deaths per 100,000 population in 1960 to 18.6 deaths per 100,000 population in 1990. Among children ages five through nine, the rates dropped from 19.6 to 9.8 .

Sherry Glied is associate professor of public health at the Mailman School of Public Health of Columbia University and a faculty research fellow of the National Bureau of Economic Research.

The author thanks James Schuttinga, NBER conference participants, and participants at the 1997 Association for Public Policy Analysis and Management conference for useful suggestions, and Sangheet Gnanasekaran for research assistance. 
Despite these large declines in mortality, unintentional injury remains the leading cause of death among children ages one through fourteen, and most of these deaths are, in some sense, avoidable (Rivara and Grossman 1996). Today, virtually all excess mortality among children in the United States relative to other industrialized countries is due to unintentional injury and violence (Centers for Disease Control 1990). Understanding the reasons for the decline in injury mortality is important to further reduce these rates. Furthermore, understanding the mechanisms that brought about the decline in child injury mortality may also inform the design of public policies aimed at reducing violent deaths among children and reducing unintentional injuries in other groups. Finally, like other improvements in health, this decline in the riskiness of childhood should figure in an assessment of changes in the cost of living. The purpose of this paper is to examine the determinants and assess the value of the decline in childhood unintentional injury mortality.

\subsection{A Model of Child Mortality from Unintentional Injury}

The recent decline in child injury mortality in the United States is characterized by two features: its pervasiveness and its timing. Accidental injury rates have declined sharply in almost every category in the International Classification of Diseases (ICD-9). Childhood mortality rates remained quite steady across most causes through the 1960s and began to decline sharply in the 1970s. The rate of decline actually accelerated over time. In both percentage terms and absolute magnitudes, declines in accidental injury rates were generally greater in the 1980s than in the 1970s.

Epidemiological literature on changes in childhood accident mortality has focused on specific steps taken to avoid injury --whether children wear seatbelts, whether pools are fenced, whether smoke detectors are installed in homes (Office of Technology Assessment 1988). These and similar interventions have been shown to be effective, but epidemiologists generally agree that at current rates of use, these interventions cannot explain a very large proportion of the change in mortality. Furthermore, the pervasiveness of these declines across disparate categories suggests that the decline in unintentional injury mortality cannot be attributed exclusively to a small number of interventions. For example, while car seats and childproof prescription bottles may have contributed to declines in automobile and poisoning deaths, specific regulations of this type cannot explain the equally substantial declines in pedestrian deaths (Rivara and Grossman 1996; Rivara 1990).

The analysis presented here takes a more general approach to trends in childhood injury mortality, relating mortality to characteristics of families and to the overall level of technology. In this approach, a decline in injury mortality from automobile accidents could be a consequence of an im- 
provement in automobile design, a decrease in the number of children the average driver must supervise, a reduction in the number of auto rides taken by children, an increase in seatbelt use, or better trauma care for children. This approach is analogous to that in most health production models (e.g., Auster, Levenson, and Sarachek 1969).

Mortality from injury in childhood can be viewed as the product of two (largely) distinct processes:

$$
\text { Mortality }=\text { Accident } \times(\text { Mortality } \mid \text { Accident }) \text {. }
$$

The first process leads to the occurrence of an accidental injury to a child. The second process generates a death as the outcome of that process. ' Improvements in childhood mortality may be a consequence of reductions in the rate of accidents or improvements in accident outcomes.

Following Grossman (1972), we can describe the first process, child safety (the absence of an accident), as the output of a household health production function. ${ }^{2}$ In the Grossman-type model, parents use technology to combine time and money inputs and produce child health:

$$
\text { Accident }=H(T, M ; E) \text {, }
$$

where $T$ represents parental time, $M$ represents parental investments in goods related to childhood safety, and $E$ represents the technology used in home production.

$$
H_{T}^{\prime}<0, \quad H_{M}^{\prime}<0, \quad H_{E}^{\prime}<0
$$

In this model, improvements in the level of child safety (reductions in accidents) may be a consequence of increases in the amount of time or money devoted to child health. These increases in time or money inputs may reflect increases in family endowments, changes in family preferences about the disposition of these endowments, or changes compelled by regulation. Alternatively, improvements in child health may be a consequence of improvements in the technology used to produce child health.

As I discuss in detail in the data section below, there were no general and substantial improvements in the resources available to families over the $1960-90$ period. Family incomes did not increase substantially, family size fell slightly, and more mothers worked. While family preferences over the disposition of resources may have changed, there is no compelling rea-

1. The processes are not completely distinct in that the severity of an accident will affect health outcomes.

2. Note that this model assumes that the parental utility value of child safety has not changed over the $1960-90$ period. This assumption is violated to the extent that improvements in other aspects of child health led parents to value children more. Such adjacent complementarities are unlikely to be substantial in this context because the absolute rate of childhood mortality, even in 1960 , was very low. 
son to believe that preferences changed substantially over the period. Instead, we focus on changes in regulations and in information.

\subsubsection{Regulation}

The late 1960s and early 1970 s were the heyday of the U.S. consumer protection movement. Child protection was an important goal of consumer protection efforts and several major federal and state legislative initiatives passed in this period focused on child safety (table 13.1). At the federal level, the Consumer Product Safety Commission produced a range of mandatory and voluntary standards designed to increase the safety of products with which children might come in contact. Products affected by the legislation included toys, children's furniture (such as cribs and changing tables), and products intended for adults that children might use. In the mid-1970s, a separate set of legislative initiatives altered the packaging of drugs to reduce the risk of child poisoning and required that children's sleepwear meet flammability standards (Consumer Product Safety Commission 1993).

At the state level, the most important initiatives focused on highway safety. Between 1977 and 1984, all states passed legislation requiring children (usually those under five) to be in a child safety seat when in an automobile (the details of the regulations vary considerably among states). A few states also required older children to wear seat belts in the front seat (Office of Technology Assessment 1988). Three states, however, rescinded laws requiring use of seat belts (among older children) during the late 1980s (Agran, Castillo, and Winn 1990). Use of vehicle restraints increased sharply during the 1980 s, especially among infants but also among older children (Johnston, Rivara, and Soderberg 1994; Agran, Castillo, and Winn 1990).

Several studies have examined the effectiveness of a few of these regulatory initiatives. The most convincing results have been found for child safety seats, which, when used properly, have been shown to reduce the risk of child mortality by about 35 percent (Office of Technology Assessment 1988).

\subsubsection{Information}

The regulatory environment of the late 1960s and early 1970s followed from, and often encouraged, the development of information about child safety. Prior to the mid-1960s, most research on child health had focused on diseases. As childhood disease mortality declined, epidemiologists' attention turned to injury and accident risks. The subfield of injury epidemiology began in the mid-1960s (Robertson 1992). The Consumer Product Safety Commission, and similar organizations, encouraged further research in these areas.

Table 13.2 provides data about the increase in the production of infor- 
Table 13.1

Public Health Legislation Affecting Children

1957

1960

1965

1966

1966

1967

1969

1970

1972

1972

1974

1975

1976

1977

1980

By 1984

1986
National Clearinghouse for Poison Control Centers

Federal Hazardous Substance Act (FHSA)

Voluntary packaging for aspirin

Child Protection Act amendment to FHSA

National Traffic and Motor Vehicle Safety Act - required that cars include safety features (e.g., shoulder belts, energy-absorbing steering assemblies)

Flammable Fabrics Act

Child Protection and Toy Safety Act amendment to FHSA

Poison Prevention Packaging Act (PPPA)

Packaging regulations for aspirin under the PPPA

Consumer Product Safety Act-issues standards; bans and recalls products; informs consumers; researches product hazards through the National Electronic Injury Surveillance System (NEISS) of sixty-four hospital emergency rooms.

Packaging regulations for prescription drugs

Automobile Fatal Accident Reporting

Bicycle regulations-bicycle must have reflectors, hand brakes that pass a pressure test, and frames that pass strength tests

First law passed requiring children to be in an infant or child seat when riding in motor vehicles

CPSC emphasizes voluntary rather than mandatory standards

All 50 states required children to be in an infant or child seat

Injury Prevention Act - to promote research and collaboration between agencies to prevent injuries

mation about childhood injury. The table lists the number of publications indexed in Medline, the main medical search index, whose subject was childhood injury in the United States. As the table suggests, publications on childhood injury have been growing steadily, both in absolute terms and as a share of all publications on children in the United States.

Injury epidemiology led directly toward injury prevention in four distinct ways. First, epidemiology led to regulation. In the mid-1960s, for example, epidemiologists in the New York City Department of Health began to examine the characteristics of child injury mortality. They found that an average of thirty to sixty children under five were dying in New York City (mainly Manhattan and the Bronx) each year because of falls from apartment buildings. This information led to a campaign to inform parents of the risk of falls and to encourage (and eventually require) landlords to install window guards. By 1980, the number of children dying because of falls in New York had declined to four (Office of Technology Assessment 1988).

Second, epidemiology provided a basis for lawsuits alleging that a defective product had led to injury. Litigation, and the fear of potential litigation, may have been a motive for the development of voluntary product safety standards in several industries. 
Table 13.2

Publications on Childhood Injury in the United States

\begin{tabular}{lccccc}
\hline & $1966-75$ & $1976-80$ & $1981-86$ & $1987-92$ & $1993-97$ \\
\hline $\begin{array}{l}\text { Annual publications } \\
\begin{array}{l}\text { Percentage of all United } \\
\quad \text { States references }\end{array}\end{array}$ & 19.1 & 24.8 & 35 & 50 & 58.4 \\
$\begin{array}{c}\text { Percentage of all references } \\
\text { to children }\end{array}$ & 0.39 & 0.36 & 0.55 & 0.54 & 0.59 \\
$\begin{array}{c}\text { Percentage of all references } \\
\text { to wounds and accidents }\end{array}$ & 0.11 & 0.12 & 0.15 & 0.21 & 0.26 \\
\hline
\end{tabular}

Source: Medline 1966-97.

Third, epidemiology led to the development of new products. As the relative risks of different causes of injury became better known, manufacturers developed a host of childproofing products to respond to the risk (Office of Technology Assessment 1988; Spock 1992).

Finally, epidemiology provided information to parents that enabled them to better allocate the resources they devoted to child health. One way to see how parents obtained this information is to compare the content of child development books over time. Table 13.3 contrasts the safety information contained in the 1957 second edition of the best-selling Dr. Spock manual of baby and child care to the information contained in the fourth edition (1976) and sixth edition (1992). Clearly, the emphasis on safety, the level of detail, and the conformity of the recommendations to epidemiologic evidence all increased substantially over time.

\subsubsection{Trauma Care}

Rates of mortality after injury vary considerably among causes of mortality. There are about thirty-two near-drowning incidents (including hospitalizations) for each child who drowns (Wintemute 1990). About 1 in 100 children who are passengers in a motor vehicle that is in an accident suffers fatal injuries (Rivara 1990). Pedestrian injury death rates are much higher. About 4 in 100 children struck by a car dies, and the rate is higher among younger children (Rivara 1990).

There were substantial increases in the availability of childhood trauma care during the $1980 \mathrm{~s}$. Trauma care is likely to have led to improvements in outcomes from burn and motor vehicle accidents (Rivara and Grossman 1996). Nonetheless, childhood trauma care lags well behind adult trauma care in saving lives. According to the medical literature, trauma care can contribute less to saving children's lives than to saving adults' lives (because children are more likely to suffer from head trauma; Office of Technology Assessment 1988). Furthermore, for several of the principal causes of death among children (particularly drowning, choking, and falls from more than three stories), most victims die before reaching a hospital (Wintemute 1990; Office of Technology Assessment 1988). 


\begin{tabular}{|c|c|c|c|}
\hline & $\begin{array}{l}\text { Spock } 1957 \text { ( } 2 \text { nd ed.), } \\
15 \text { million copies sold }\end{array}$ & $\begin{array}{l}\text { Spock } 1976(4 \text { th ed. }) \\
28 \text { million copies sold }\end{array}$ & $\begin{array}{l}\text { Spock } 1992 \text { ( } 6 \text { th ed.), } \\
40 \text { million copies sold }\end{array}$ \\
\hline Section title & "Avoiding Accidents and Fears" & "Avoiding Accidents" & "Preventing Injuries" \\
\hline Location & "One Year Old" section & "One Year Old" section & Entire chapter \\
\hline Length & 3 pages & 5 pages & $\begin{array}{l}13 \text { pages + } 1 \text { paragraph in "One Year Old" } \\
\text { section }\end{array}$ \\
\hline Preamble & $\begin{array}{l}\text { One year is a dangerous age. } \\
\text { Parents cannot prevent all } \\
\text { injuries. If they were careful } \\
\text { enough or worrisome enough, } \\
\text { they would only make a child } \\
\text { timid. }\end{array}$ & $\begin{array}{l}\text { Accidents are now the biggest } \\
\text { cause of death. ( } 1957 \text { preamble } \\
\text { appears later) }\end{array}$ & $\begin{array}{l}\text { "Injuries now cause more deaths in children over } \\
\text { the age of } 1 \text { year than all illnesses combined. } \\
\text { The three leading causes of these injuries are } \\
\text { motor vehicles, fire . . . and drowning." Two } \\
\text { basic principles: awareness and supervision. } \\
\text { (1957 preamble appears later) }\end{array}$ \\
\hline \multirow[t]{19}{*}{ Cautions } & high chair & high chair & high chair \\
\hline & baby carriage & baby carriage & baby carriage \\
\hline & stairs & stairs & stairs \\
\hline & windows & windows & windows \\
\hline & pot handles & pot handles & pot handles \\
\hline & small objects & small objects & small objects \\
\hline & bath temperature & bath temperature & bath temperature \\
\hline & cover wall sockets with tape & outlet covers & outlet covers \\
\hline & tools & tools & tools \\
\hline & medicine and poisons & medicine and poisons & medicine and poisons \\
\hline & & car seats & car seats \\
\hline & & seat belts & seat belts \\
\hline & & pedestrian safety & pedestrian safety \\
\hline & & fire extinguisher & fire extinguisher \\
\hline & & clothes flammability & clothes flammability \\
\hline & & tub drowning & tub drowning \\
\hline & & & bicycle helmets \\
\hline & & & hot water heater \\
\hline & & & smoke detectors \\
\hline
\end{tabular}




\subsubsection{The Relationship between Regulation, Technology, and Postaccident Care and Family Resources}

Table 13.4 categorizes the range of changes in the child health environment over the 1960-90 period. Some new information was transmitted entirely through private actions (such as Dr. Spock's books; see table 13.3). Other information was transmitted through regulations requiring safety labeling. Product quality improvements followed regulations and informational developments. Finally, regulations also imposed requirements on parents and others to make use of available safety equipment.

These different environmental changes are likely to have had different types of effects. Furthermore, the effects are likely to have differed across different types of families.

In the context of the child health production model, information that leads parents to recognize risks of which they were previously unaware (or better responses to risks), can lead to reallocations of time and money that allow the production of better health at the same cost. That is, this information improves the technology for production of health. If information is conveyed through voluntary mechanisms, better educated parents are more likely to have access to it. Labeling requirements may convey information to both more educated and less educated parents.

Regulation, by itself, will not have a substantial effect on child health in the standard health production model. In the case of behavioral regulations, if families are required to increase certain inputs for child health beyond what they would otherwise choose, they are likely to reduce other inputs accordingly. Furthermore, behavioral regulations can have perverse effects (Peltzman 1975). For example, requiring small children to use car

Table 13.4

Types of Interventions

\begin{tabular}{|c|c|c|}
\hline Class of Change & Purpose & Examples \\
\hline Nonregulatory information & Awareness of hazards & Hot dogs, grapes, balloons \\
\hline Regulatory information & Labeling & $\begin{array}{l}\text { Toy labels, plastic bag } \\
\text { labels }\end{array}$ \\
\hline $\begin{array}{l}\text { Regulatory and nonregulatory } \\
\text { improvements in product } \\
\text { quality }\end{array}$ & $\begin{array}{l}\text { Reduce risks of } \\
\text { existing products }\end{array}$ & $\begin{array}{l}\text { Refrigerator and freezer } \\
\text { door standards, crib slat } \\
\text { design standards, } \\
\text { clothing flammability } \\
\text { standards, safety caps } \\
\text { for pharmaceuticals }\end{array}$ \\
\hline $\begin{array}{l}\text { Regulatory and nonregulatory } \\
\text { development of safety } \\
\text { technologies }\end{array}$ & $\begin{array}{l}\text { New products to } \\
\text { reduce risks }\end{array}$ & $\begin{array}{l}\text { Smoke detectors, window } \\
\text { guards, car seats, outlet } \\
\text { plugs, rail guards, bike } \\
\text { helmets, scald guards }\end{array}$ \\
\hline Behavioral safety regulation & $\begin{array}{l}\text { Requirements that } \\
\text { consumers comply } \\
\text { with standards }\end{array}$ & Seat belt laws \\
\hline
\end{tabular}


seats may reduce the mortality of these children, but it could lead to increases in the mortality of older children if parents now drive faster.

Regulations that increase the cost of products, such as rules requiring toys and child furniture to meet new standards, will favor higher-income children. High-income children will benefit when their parents purchase the new products. Low-income families, however, may delay purchasing new products or may purchase secondhand products, potentially increasing the risks facing their children. These regulations may also favor lower birth order children if parents purchase new products for their firstborn children and then pass them along to younger siblings.

Regulation can be effective, however, if it serves as a means of conveying new information to parents. To the extent that regulations substitute for information that would otherwise be available in the private market, they may reduce the production advantages of better educated parents.

Better trauma care is likely to improve outcomes for all children. While high-income children may have better access to physician services, trauma care is provided through emergency rooms that must take all patients. Higher-income children and children outside rural areas may, however, be more likely to be located near a pediatric trauma center.

\subsection{Empirical Strategy and Data}

In principle, the model described in equation (1) should be tested in two stages: the probability of accident and the risk of mortality conditional on accident. Unfortunately, there is little data on the rate of accidents generally. Instead, I examine the determinants of mortality.

The theory of health production suggests that changes in mortality may be a consequence of changes in time or money inputs or changes in technology. I conduct two (closely related) sets of analyses to examine the roles of changes in inputs and to assess the nature, and role, of changes in technology. First, I estimate a model of the production of child injury mortality by cause in the 1960s as a function of family time and money inputs in that period. I then use the estimated production function to project child mortality by cause in 1980 and 1990 given the characteristics of children and their families in these later years. I compare the projected and actual mortality figures to assess the role of changes in measured inputs over this period. The residual is an estimate of the role of changing health production technology.

Second, I reestimate the model of health production using data from 1980 and 1990. I then compare the coefficients of key variables to assess how technology altered the production function for child health. The changes in the coefficients provide an indication of how the empirical changes in the production of child health conform to those predicted by a health production model.

Third, I assess the value of these changes in child health. I measure this 
value by imputing a value to the lives of children saved through improvements in technology.

\subsubsection{Data}

Even in 1960, childhood injury mortality was (thankfully) a rare event. In consequence, standard data sets that include children do not contain enough observations on serious childhood injury or mortality to serve as the basis of an empirical investigation of its determinants. Longitudinal mortality databases focus on mortality in the adult population and, in the few cases that include children, contain too few children to assess the covariates of mortality. Furthermore, these databases do not allow us to examine changing patterns in child mortality over time. Instead, I construct a database by combining data from the National Mortality Detail Files with data from the Current Population Survey.

The National Mortality Detail Files contain a record of every death recorded in the United States. Information in the file includes the state of residence of the decedent, the decedent's age, and the cause of death. I use data from the 1968, 1969, 1970, 1978, 1979, 1980, 1988, 1989, and 1990 detail files. I select all deaths among children ages one through twelve that occurred because of unintentional injury ( $E$ codes). I then group these causes into several broad categories and focus my analysis on total unintentional injury mortality and on the four most common causes of childhood injury mortality: automobile accidents, pedestrian accidents, fires, and drowning. I also examine mortality due to falls among children ages one through five. I group deaths into two categories: preschool-age children (ages one through five) and elementary school age children (ages six through twelve). I combine data for 1968-70, 1978-80, and 1988-90 to increase the cell sizes.

The Current Population Survey (CPS) contains demographic and economic information on adults and children in the United States. CPS data before 1968 do not contain information on children so I begin my analysis with the 1968 sample. In each CPS year, I identify all families that contain a child aged one through twelve. I then measure (separately) the average characteristics of families with children ages one through five and ages six through twelve in each state in the United States. Prior to 1973, the CPS combines states into thirty regions, so my analysis is limited to these regions. After 1973, I use data at the state level. Sample sizes for children are quite small, especially in the smaller states. To reduce variability in the data, I compute averages of each variable in each state over the three-year periods above (weighted by the number of observations for that year in that state). ${ }^{3}$ Because of the high sampling variability in the CPS, I obtain

3. I analyzed the data both using and not using the CPS weights. I report unweighted results here, but use of the weights makes no substantial difference to the results. 
counts of children in each age group in each state from the decennial censuses (1970, 1980, and 1990).

The health production model suggests that parental time and money, and technology are the principal inputs in the production of child health. I proxy parental time inputs with five variables: whether the mother is currently married, whether the mother works, how many infants (birth to one year) are in the family, how many preschool-aged children (ages one through five) are in the family, and how many older children (ages six through twelve) are in the family. I expect that married mothers and nonworking mothers are likely to be able to devote more time to their children. Mothers with infants are likely to have less time to devote to their older children. The existence of more children of the same age as the index child within a family may improve health, to the extent that there are economies of scale in child safety. Older children may be able to help out and reduce injuries among their younger siblings; alternatively, they may expose their siblings to additional hazards, especially if safety equipment is handed down from child to child in a family. Changes in safety regulations aimed at younger children, however, may increase the hazard to older siblings.

In a very small number of CPS families, no mother is present in the household. In these families, I code the head of household, regardless of sex, as the "mother." A variable for the average percentage of households in a state without a mother present was never large or significant in any of the analyses.

Table 13.5 provides data on the characteristics of families in 1968, 1978, and 1988. In the period since 1968, parental time variables have moved in different directions. More mothers are working and fewer are married. Families are smaller, however, and children are much less likely to have older or younger siblings in the later years than in the early data.

The second set of inputs in the health production model is money spent on child safety. I use two variables to measure these money inputs. First, I measure average family income for families with children ages one through five and families with children ages six through twelve (note that, as discussed above, I also control for the number of children one through twelve in these families). Family income, measured in 1968 dollars, declined in the middle period and returned to just above 1968 levels in the later period. Second, I measure the physical environment of children in each age group. I include variables for the fraction of children who live in central cities and the fraction who live in Standard Metropolitan Statistical Areas (SMSAs). Changes in children's physical environments are likely to have important effects on their well-being. The types of accidents that occur are likely to be different in cities than in rural areas. For example, drowning deaths are rare in central cities, more common among younger children in suburban areas (where private swimming pools exist), and more common among older children in rural areas (where natural bodies of wa- 
Table 13.5 Characteristics of CPS Families

\begin{tabular}{|c|c|c|c|}
\hline & 1970 & 1980 & 1990 \\
\hline \multicolumn{4}{|c|}{ Characteristics of Families of Children 1-5 (state averages) } \\
\hline Census count of children $(1,000 \mathrm{~s})$ & 17,479 & 15,869 & 18,445 \\
\hline Family income (1968\$) & $8,434.67$ & $7,602.14$ & $8,608.74$ \\
\hline Children under 1 & 0.14 & 0.12 & 0.12 \\
\hline Children 1-5 & 1.65 & 1.51 & 1.51 \\
\hline Children 6-12 & 0.95 & 0.61 & 0.58 \\
\hline Mother's education & 11.12 & 11.59 & 11.65 \\
\hline Mother works & 0.26 & 0.38 & 0.47 \\
\hline Currently married & 0.88 & 0.81 & 0.74 \\
\hline Central city & 0.27 & 0.22 & 0.25 \\
\hline SMSA & 0.38 & 0.27 & 0.33 \\
\hline Nonwhite & 0.16 & 0.20 & 0.22 \\
\hline \multicolumn{4}{|c|}{ Characteristics of Families of Children 6-12 (state averages) } \\
\hline Census count of children ( $1,000 \mathrm{~s})$ & 28,835 & 24,509 & 24,870 \\
\hline Family income $(1968 \$)$ & $9,722.65$ & $8,725.90$ & $9,610.22$ \\
\hline Children under 1 & 0.06 & 0.05 & 0.05 \\
\hline Children $1-5$ & 0.58 & 0.41 & 0.43 \\
\hline Children 6-12 & 2.24 & 1.80 & 1.72 \\
\hline Mother's education & 11.05 & 11.53 & 11.93 \\
\hline Mother works & 0.36 & 0.49 & 0.57 \\
\hline Currently married & 0.87 & 0.79 & 0.75 \\
\hline Central city & 0.26 & 0.21 & 0.23 \\
\hline SMSA & 0.39 & 0.29 & 0.32 \\
\hline Nonwhite & 0.15 & 0.19 & 0.22 \\
\hline
\end{tabular}

Note: $N=29,1968-70 ; N=50$ thereafter.

ter pose a hazard). Families have moved out of central cities, and, to a lesser extent, out of SMSAs over this period.

I include the average level of mother's education as a measure of the technology for producing child health. Finally, I include a measure of the percentage of a state's child population (in each age group) that is nonwhite as a control. I exclude observations for the District of Columbia, leaving a data set with twenty-nine observations in 1968-1970 and fifty observations in 1978-1980 and 1988-1990.

\subsubsection{Statistical Method}

The data set constructed by combining CPS and Vital Statistics data contains counts of child deaths (by cause), counts of children from the census, and average values of family characteristics, each measured as state averages. Because the dependent variable data are measured as counts, I use negative binomial regression methods for the analysis. ${ }^{4}$

I constrain the coefficient on the (log of the) count of children from the

4. I reject the hypothesis that the data are distributed as a Poisson for every analysis. 
census to be equal to $1 .^{5}$ I estimate this regression separately for the 1968 $70,1978-80$, and 1988-90 data. I use the estimated coefficients from the negative binomial regression to predict the expected number of deaths in subsequent years using the values of the independent variables in those years.

The coefficients from the negative binomial regression describe the effect of increasing an independent variable by one unit on the log of deaths from a particular cause. As an easier-to-interpret alternative, I simulate elasticities of response of cause-specific deaths to changes in the independent variables. I increase the value of each independent variable for each observation in turn by 1 percent (holding all other independent variables at their original values) and then compute the percentage change in the predicted mean for that cause of death. For example, I compute the percentage effect on pedestrian deaths among one through five year olds by increasing the average family income of families with one through five year olds by 1 percent.

\subsection{Results}

I initially estimate the mortality regressions using data for 1968-70. Coefficients and standard errors from these specifications are reported in table 13.6 for each cause of death and each age group.

Among younger children, average family characteristics explain 5-10 percent of the variation in childhood mortality at the state level. Parental time variables are important contributors to child mortality for some causes of death in 1968-70. States with more working mothers tend to have greater rates of all causes of child mortality than do those in which fewer mothers work. These states have significantly higher rates of automobile deaths and pedestrian deaths. Based on the simulation results (not reported in table), a l percent increase in the proportion of mothers working would increase the count of child automobile and pedestrian deaths in a state by 0.7 percent and 0.5 percent, respectively. The presence of older or younger children also tends to raise the risk of mortality for several causes of injury. Increasing the average number of infants in a family by 1 percent raises pedestrian deaths among those ages one through five by about 0.5 percent. There is some evidence of economies of scale in child safety production. States where the average one- to five-year-old has more preschool-age siblings have substantially and significantly lower rates of mortality among those ages one through five.

Family income is a significant predictor of childhood mortality only for automobile mortality among one- to five-year-olds in 1968-70, and for

5. In a separate set of regressions in which I did not constrain the coefficient, I can (almost) always reject the hypothesis that this coefficient is significantly different from 1 . 
Table 13.6

Production of Mortality, 1968-70

\begin{tabular}{|c|c|c|c|c|c|c|}
\hline & Auto & Pedestrian & Falls & Fire & Drowning & All \\
\hline \multicolumn{7}{|c|}{ Children 1-5 } \\
\hline \multirow[t]{2}{*}{ Constant } & $-9.019^{*}$ & $-5.140^{*}$ & $-15.138^{*}$ & $-9.691^{*}$ & -6.331 & $-5.271^{*}$ \\
\hline & $(3.047)$ & $(1.580)$ & (3.532) & $(1.959)$ & $(4.976)$ & $(1.499)$ \\
\hline \multirow[t]{2}{*}{ Income } & $-0.0002^{* * *}$ & 0.00003 & 0.00001 & -0.00005 & -0.0001 & $0.0001^{* * *}$ \\
\hline & $(0.000)$ & $(0.000)$ & $(0.000)$ & $(0.000)$ & $(0.000)$ & $(0.000)$ \\
\hline \multirow[t]{2}{*}{ Babies } & 2.278 & $4.610^{* *}$ & -1.687 & -2.815 & 6.791 & 1.295 \\
\hline & $(3.337)$ & $(1.828)$ & $(4.176)$ & $(2.169)$ & $(5.577)$ & $(1.673)$ \\
\hline \multirow[t]{2}{*}{$1-5$ years } & $-3.388^{* *}$ & $-1.368^{* * *}$ & 2.648 & 0.106 & -2.729 & $-1.587^{* * *}$ \\
\hline & $(1.738)$ & $(0.807)$ & $(1.890)$ & $(1.064)$ & $(2.965)$ & $(0.850)$ \\
\hline \multirow[t]{2}{*}{$6-12$ years } & 0.862 & 0.533 & -0.778 & -0.080 & 0.748 & 0.455 \\
\hline & $(0.613)$ & $(0.332)$ & $(0.748)$ & $(0.383)$ & $(1.123)$ & $(0.306)$ \\
\hline \multirow{2}{*}{$\begin{array}{l}\text { Mom's } \\
\text { education }\end{array}$} & -0.040 & -0.144 & 0.062 & $-0.288 * *$ & 0.495 & 0.094 \\
\hline & $(0.189)$ & $(0.097)$ & $(0.221)$ & $(0.120)$ & $(0.329)$ & $(0.093)$ \\
\hline \multirow[t]{2}{*}{ Mom works } & $2.281^{* * *}$ & $1.623^{* *}$ & -2.392 & $-2.459^{*}$ & 2.653 & 0.778 \\
\hline & $(1.370)$ & $(0.674)$ & $(1.606)$ & $(0.842)$ & $(2.186)$ & $(0.669)$ \\
\hline \multirow{2}{*}{$\begin{array}{l}\text { Mom } \\
\text { married }\end{array}$} & 6.934 & -1.904 & 1.490 & $6.085^{* *}$ & -5.736 & -0.322 \\
\hline & $(4.747)$ & $(2.198)$ & $(4.972)$ & $(2.769)$ & $(8.304)$ & $(2.274)$ \\
\hline \multirow[t]{2}{*}{ Central city } & $1.404^{* *}$ & 0.123 & -0.454 & $-0.689^{* *}$ & 0.654 & $0.625^{* *}$ \\
\hline & $(0.583)$ & $(0.284)$ & $(0.634)$ & $(0.352)$ & $(0.924)$ & $(0.283)$ \\
\hline \multirow[t]{2}{*}{ SMSA } & 0.308 & $0.559 * * *$ & 0.137 & -0.395 & 1.173 & 0.145 \\
\hline & $(0.640)$ & $(0.302)$ & $(0.695)$ & $(0.392)$ & $(1.019)$ & $(0.308)$ \\
\hline \multirow[t]{2}{*}{ Nonwhite } & 1.630 & -0.241 & 0.270 & $2.907^{*}$ & -0.837 & 0.875 \\
\hline & $(0.996)$ & $(0.511)$ & (1.115) & $(0.611)$ & $(1.531)$ & $(0.476)$ \\
\hline$R^{2}$ & 0.07 & 0.10 & 0.05 & 0.16 & 0.04 & 0.06 \\
\hline$Z$ & n.s. & 0.08 & n.s. & 0.07 & n.s. & n.s. \\
\hline
\end{tabular}




\begin{tabular}{|c|c|c|c|c|c|}
\hline \multirow{3}{*}{ Constant } & \multicolumn{4}{|c|}{ Children 6-12 } & \multirow{3}{*}{$\begin{array}{r}-8.019^{*} \\
(0.926)\end{array}$} \\
\hline & $-11.193^{*}$ & $-5.395^{*}$ & $-12.013^{*}$ & $-10.434^{*}$ & \\
\hline & $(1.956)$ & $(1.704)$ & $(2.356)$ & $(1.758)$ & \\
\hline \multirow[t]{2}{*}{ Income } & $-0.0002^{* *}$ & $(0.0001)$ & 0.000 & $-0.0002^{* *}$ & $-0.0001^{*}$ \\
\hline & $(0.000)$ & $(0.000)$ & $(0.000)$ & $(0.000)$ & $(0.000)$ \\
\hline \multirow[t]{2}{*}{ Babies } & $9.596^{* * *}$ & 6.717 & 7.841 & 4.374 & $5.344^{* *}$ \\
\hline & $(5.203)$ & $(4.744)$ & $(6.136)$ & $(4.560)$ & $(2.503)$ \\
\hline \multirow[t]{2}{*}{$1-5$ years } & $-1.257^{* * *}$ & 0.160 & -0.630 & -0.046 & -0.399 \\
\hline & $(0.750)$ & $(0.675)$ & $(0.932)$ & $(0.703)$ & $(0.361)$ \\
\hline \multirow[t]{2}{*}{$6-12$ years } & $1.593^{*}$ & -0.642 & -1.002 & $1.668^{*}$ & $0.930^{*}$ \\
\hline & $(0.590)$ & $(0.526)$ & $(0.733)$ & $(0.547)$ & $(0.283)$ \\
\hline \multirow{2}{*}{$\begin{array}{l}\text { Mom's } \\
\text { education }\end{array}$} & $0.228^{* * *}$ & $-0.380^{*}$ & -0.047 & 0.194 & $0.148^{* *}$ \\
\hline & $(0.137)$ & $(0.130)$ & $(0.179)$ & $(0.126)$ & $(0.067)$ \\
\hline \multirow{2}{*}{$\begin{array}{l}\text { Mom's } \\
\text { works }\end{array}$} & 1.206 & 0.639 & -1.379 & $1.724^{* *}$ & 0.643 \\
\hline & $(0.850)$ & $(0.752)$ & $(1.049)$ & $(0.771)$ & $(0.406)$ \\
\hline \multirow{2}{*}{$\begin{array}{l}\text { Mom } \\
\text { married }\end{array}$} & -2.552 & 0.375 & $6.637^{* * *}$ & $-4.464^{* * *}$ & $-2.670^{* * *}$ \\
\hline & $(2.931)$ & $(2.709)$ & $(3.695)$ & $(2.660)$ & $(1.422)$ \\
\hline \multirow[t]{2}{*}{ Central city } & 0.262 & $-0.908^{* *}$ & -0.772 & -0.092 & -0.170 \\
\hline & $(0.455)$ & $(0.403)$ & $(0.555)$ & $(0.403)$ & $(0.217)$ \\
\hline \multirow[t]{2}{*}{ SMSA } & -0.104 & 0.364 & $1.096^{* * *}$ & 0.015 & -0.020 \\
\hline & $(0.488)$ & $(0.429)$ & $(0.589)$ & $(0.438)$ & $(0.233)$ \\
\hline \multirow[t]{2}{*}{ Nonwhite } & -0.138 & -0.046 & $2.041^{* *}$ & 0.180 & 0.242 \\
\hline & $(0.675)$ & $(0.620)$ & $(0.851)$ & $(0.601)$ & $(0.325)$ \\
\hline$R^{2}$ & 0.08 & 0.10 & 0.10 & 0.12 & 0.11 \\
\hline$Z$ & 0.09 & n.s. & 0.10 & 0.03 & 0.04 \\
\hline
\end{tabular}

Notes: Coefficients from negative binomial regression. Population coefficient $=1$. Standard errors in parentheses. n.s. $=$ not significant.

${ }^{*} p<0.01 ;{ }^{* *} p<0.05 ;{ }^{* * *} p<0.10$. 
some causes of death the coefficient on income is small and positive. Overall, a 1 percent increase in income is associated with a 0.8 percent decline in mortality rates. The geographic distribution of children has varying effects depending on the particular cause of death. Overall, children in states that have more population in central cities have higher rates of mortality.

Mother's education has small, often negative, but rarely significant effects on preschool mortality in the one through five year age group. The proportion of children who are nonwhite greatly increases the risk of fire deaths, but does not contribute substantially to death from other causes.

Table 13.6 reports results for elementary school children ages six through twelve. In general, patterns of results are quite similar across the two age groups. Parental time variables, as a group, are important contributors to child mortality for all causes of death except pedestrian mortality. In states with more working mothers, childhood mortality rates from most causes are higher, sometimes significantly higher. The presence of infants also consistently increases the risk of childhood mortality among elementary school children. A 1 percent increase in the average number of infants in families of six- to twelve-year-olds raises mortality rates in this group by about 0.3 percent.

Family income is a more important determinant of childhood mortality among this older age group. For all causes, automobile accidents, and drowning deaths, children in states with higher average family income are at lower risk. A 1 percent increase in average family income reduces the risk of death from these causes by 1.6 percent. The geographic distribution of families has limited and inconsistent effects on mortality outcomes.

Mother's education has an unexpectedly positive effect on mortality for all causes, automobile accidents, and drowning deaths. This result may reflect unmeasured characteristics of families with more educated mothers. The nonwhite proportion again increases the risk of fire deaths but has little correlation with other causes of death.

\subsubsection{Predicting Mortality}

The results of the 1968-70 study suggest that changes in the living circumstances of children over the 1968-90 period may have contributed to changes in child mortality. In particular, the decline in the number of infants in households should have reduced mortality, while the increase in the proportion of mothers who work would have been expected to lead to an increase in mortality. Other changes may also have affected mortality outcomes.

To assess the role of these changes, I use the 1968-70 coefficients to predict rates of mortality given annual average living circumstances for 1970 , 1980, and 1990. Actual counts of deaths; extrapolations for all causes, automobile accidents, and pedestrian deaths; and extrapolations based on constant rates of mortality are shown in table 13.7. 
Table 13.7

Counts of Deaths, Extrapolations, Predictions, and Errors, by Cause and Age Group

\begin{tabular}{|c|c|c|c|c|c|}
\hline Cause & Actual & Extrapolation & Prediction & $\begin{array}{c}\text { Extrapolation } \\
\text { Error (\%) }\end{array}$ & $\begin{array}{l}\text { Prediction } \\
\text { Error (\%) }\end{array}$ \\
\hline \multicolumn{6}{|c|}{ Children $1-5$} \\
\hline \multicolumn{6}{|l|}{ Auto } \\
\hline 1970 & 1,066 & 1,066 & 1,124 & 0 & -5 \\
\hline 1980 & 859 & 969 & 1,161 & -13 & -35 \\
\hline 1990 & 722 & 1,121 & 764 & -55 & -6 \\
\hline \multicolumn{6}{|c|}{ Pedestrian } \\
\hline 1970 & 963 & 963 & 1,037 & 0 & -8 \\
\hline 1980 & 575 & 875 & 1,032 & -52 & -79 \\
\hline 1990 & 374 & 1,013 & 1,569 & -171 & -320 \\
\hline \multicolumn{6}{|l|}{ Total } \\
\hline 1970 & 5,696 & 5,696 & 6,253 & 0 & -10 \\
\hline 1980 & 4,228 & 5,175 & 7,552 & -22 & -79 \\
\hline 1990 & 3,365 & 5,989 & 8,706 & -78 & -159 \\
\hline \multicolumn{6}{|c|}{ Children 6-12 } \\
\hline \multicolumn{6}{|l|}{ Auto } \\
\hline 1970 & 1,379 & 1,379 & 1,298 & 0 & 6 \\
\hline 1980 & 1,019 & 1,173 & 1,179 & -15 & -16 \\
\hline 1990 & 816 & 1,192 & 1,185 & -46 & -45 \\
\hline \multicolumn{6}{|c|}{ Pedestrian } \\
\hline 1970 & 1,223 & 1,223 & 1,191 & 0 & 3 \\
\hline 1980 & 702 & 1,040 & 965 & -48 & -37 \\
\hline 1990 & 465 & 1,057 & 1,021 & -127 & -120 \\
\hline \multicolumn{6}{|l|}{ Total } \\
\hline 1970 & 5,522 & 5,522 & 5,308 & 0 & 4 \\
\hline 1980 & 3,420 & 4,698 & 5,047 & -37 & -48 \\
\hline 1990 & 2,409 & 4,774 & 5,385 & -98 & -124 \\
\hline
\end{tabular}

Note: Predictions based on regressions in table 13.6. Extrapolations constructed by holding death rate constant and adjusting for size of population at risk.

For children ages one through five, the prediction regressions substantially overpredict total mortality in the later years. Actual mortality is less than one-third as high as expected. A simple linear extrapolation of death rates overpredicts mortality by about 80 percent.

Differences in mortality counts are relatively small for automobile deaths. This close correspondence is rather surprising because automobile safety was the primary subject of child safety regulation during the 1970 s and 1980s. These results suggest that improvements in child safety because of regulations and design changes were offset by increased use of automobiles by children, or that such safety measures had a relatively minor impact on child mortality. The finding is consistent with epidemiologic studies that find surprisingly little correlation between the time series of safety restraint use rates and the time series of automobile fatalities (Agran, Castillo, and Winn 1990). 
By contrast, the results of the prediction analysis for pedestrian mortality are sharply higher than actual pedestrian mortality rates. By 1990, the prediction estimates are more than four times as high as the actual figures. The prediction estimates are higher than extrapolations based on constant rates mainly because of the substantial increase in labor force participation rates among mothers of young children. The prediction regressions thus show that pedestrian mortality was expected to increase somewhat over this period. In fact, pedestrian mortality declined by 65 percent. Epidemiologists have noted the large declines in pedestrian mortality but have not been able to explain the observed patterns, especially in this younger age group (Rivara and Grossman 1996).

The prediction regression for deaths from falls (not shown in the table) almost precisely predicts the actual death rate. The prediction for deaths from fires (not shown in the table) strongly underpredicts the actual death rate. ${ }^{6}$ Together with motor vehicle accidents, these two areas are those where improvements in pediatric trauma care might have been expected to have substantial effects. The finding that there was relatively less overprediction for these rates than for other causes suggests that improvements in medical care were not the primary reason for reductions in death rates in this age group.

The second panel of table 13.7, presents results for older children. Again, predicted all-cause mortality is more than twice as high as actual mortality. Differences between extrapolations and predictions are quite small for older children. In general, the prediction errors are slightly larger than the extrapolation errors.

The decline in automobile passenger mortality among children ages six through twelve was much steeper than among younger children and was not predicted by the initial regression. In most states, children ages six through twelve were not required to use auto safety restraints during the period under study. Most children did use such restraints, but use of restraints was less frequent in the older age group than among younger children (Johnston, Rivara, and Soderberg 1994). In combination with the results for one- to five-year-olds (who were affected by the regulations), the results for six- to twelve-year-olds whose behavior was not governed by child safety regulations suggest that regulatory changes aimed at child safety seat use are not as important an explanation for declines in mortality as might have been expected. Improvements in trauma treatment may have been an important factor in reducing mortality in this group.

Declines in pedestrian mortality were also steep among older children. Since younger children have very different walking patterns than older children, the combination of results for younger and older children sug-

6. The prediction for drowning deaths is unrealistically high for unknown reasons (the prediction error is 640 percent). 
gests that greater use of school crossing guards or similar interventions cannot explain most of the change in pedestrian mortality. One explanation for the lower rate of pedestrian injury in older children is that they are less likely to walk to school alone now than they were twenty years ago (Rivara and Grossman 1996). This explanation is consistent with the pattern for older children, but does not explain the similar decline in mortality among younger children.

\subsubsection{Changes in the Production of Child Safety}

The discrepancies between the predicted and actual estimates of child mortality suggest that the decline in child mortality is not simply a consequence of a change in the inputs to health production. There is also likely to have been a change in the technology for producing child health. To investigate this possibility, I reestimate the regressions using data for 1968-70, 1978-80, and 1989-91. I include interaction effects for years after 1968 and for years after 1988 . To simplify the comparison, table 13.8 reports coefficients for selected variables of interest.

We first examine the changing role of parental time in producing child safety. The effect of mothers' working on child mortality declines over time for most causes of death. The decline is stronger for older children than for younger children. By 1990, the proportion of mothers working in a state has essentially no effect on all-cause mortality for school children. The results for the presence of infants in the family (not reported in the table) show a similar declining pattern for both age groups. This result suggests that products and services (including formal day care) are increasingly valuable alternatives to parental time in the production of child health.

The role of family income varies over time but does not become important over this period for most causes of death in either age group. A growing role for family income is likely to occur when regulations mandate improvements in product quality or when new costly safety-improving technologies are introduced. For example, higher family income may reduce automobile passenger deaths if safer cars are more costly than less safe cars.

Mother's education plays a much greater beneficial role in reducing childhood injury after 1970 than in the early period, especially among younger children. This finding is consistent with the considerable expansion in information about childhood injury that became available in the 1970 s and 1980s. Increases in information are likely to widen the gap between less and more educated families.

I had hypothesized that the presence of older siblings in a family might reduce the safety of younger children to the extent that families made time investments in safety technology. I assess this hypothesis by comparing the effect of the presence of older siblings on mortality among one- to five- 


\begin{tabular}{|c|c|c|c|c|c|c|}
\hline & Auto & Pedestrian & Falls & Fire & Drowning & All \\
\hline \multicolumn{7}{|c|}{ Children I--5 } \\
\hline \multirow[t]{2}{*}{ Income } & $-0.0002 * *$ & 0.0000 & 0.0000 & -0.0001 & -0.0001 & -0.0001 \\
\hline & $(0.0001)$ & $(0.0001)$ & $(0.0001)$ & $(0.0002)$ & $(0.0002)$ & $(0.0001)$ \\
\hline \multirow[t]{2}{*}{ Income $80 / 90$} & $0.0002 * * *$ & -0.0001 & 0.0001 & 0.0000 & 0.0002 & $0.000 \mathrm{l}$ \\
\hline & $(0.0001)$ & $(0.0001)$ & $(0.0002)$ & $(0.0002)$ & $(0.0002)$ & $(0.0001)$ \\
\hline \multirow[t]{2}{*}{ Income 90} & $-0.0002 * * *$ & 0.0001 & 0.0000 & -0.0001 & -0.0001 & -0.0001 \\
\hline & $(0.0001)$ & $(0.0001)$ & $(0.0002)$ & $(0.0001)$ & $(0.0001)$ & $(0.0000)$ \\
\hline \multirow[t]{2}{*}{$6-12$} & 0.8692 & 0.5436 & -0.7586 & -0.1066 & 0.7679 & 0.4561 \\
\hline & $(0.5543)$ & $(0.3428)$ & $(0.6916)$ & $(0.7389)$ & $(0.9263)$ & $(0.2987)$ \\
\hline \multirow[t]{2}{*}{$6-1280 / 90$} & $2.0782 * *$ & 0.7227 & -0.3511 & 0.8055 & $3.4039^{* *}$ & $1.7120 *$ \\
\hline & $(0.8797)$ & $(0.6534)$ & $(1.3537)$ & $(1.1766)$ & $(1.3590)$ & $(0.4790)$ \\
\hline \multirow[t]{2}{*}{$6-1290$} & $-2.4317^{* *}$ & -0.4978 & 2.0790 & -0.9368 & $-2.9832 * *$ & $-1.5431^{*}$ \\
\hline & $(0.9964)$ & $(0.9020)$ & $(1.6260)$ & $(1.3980)$ & $(1.4565)$ & $(0.5197)$ \\
\hline \multirow[t]{2}{*}{ Mom's education } & -0.0437 & -0.1452 & 0.070 & -0.2790 & $0.4954 * * *$ & 0.0944 \\
\hline & $(0.1710)$ & $(0.1005)$ & $(0.2042)$ & $(0.2330)$ & $(0.2709)$ & $(0.0904)$ \\
\hline \multirow{2}{*}{$\begin{array}{l}\text { Mom's education } \\
80 / 90\end{array}$} & -0.2732 & -0.1201 & -0.0358 & 0.2184 & $-0.7840^{* *}$ & $-0.2199 * *$ \\
\hline & $(0.1984)$ & $(0.1228)$ & $(0.2533)$ & $(0.2731)$ & $(0.3068)$ & $(0.1047)$ \\
\hline \multirow{2}{*}{$\begin{array}{l}\text { Mom's education } \\
90\end{array}$} & 0.2278 & -0.0381 & -0.0276 & 0.2819 & -0.0606 & 0.0390 \\
\hline & $(0.1408)$ & $(0.1001)$ & $(0.2030)$ & $(0.2011)$ & $(0.2012)$ & $(0.0734)$ \\
\hline \multirow[t]{2}{*}{ Mom works } & $2.3615^{* * *}$ & $1.6306^{* *}$ & -2.3586 & -2.5598 & 2.8559 & 0.7855 \\
\hline & $(1.2352)$ & $(0.7037)$ & $(1.4814)$ & $(1.6735)$ & $(1.8204)$ & $(0.6525)$ \\
\hline \multirow{2}{*}{$\begin{array}{l}\text { Mom works } 80 / \\
90\end{array}$} & 0.1112 & -1.0149 & 0.1404 & 1.4320 & 0.3807 & 0.2902 \\
\hline & $(1.4550)$ & $(0.8929)$ & $(1.8614)$ & $(1.9416)$ & $(2.1336)$ & $(0.7630)$ \\
\hline \multirow[t]{2}{*}{ Mom works 90} & -0.2358 & -0.1918 & 1.0931 & -1.1243 & -0.1007 & -0.5804 \\
\hline & $(1.1152)$ & $(0.9001)$ & $(1.6543)$ & $(1.4397)$ & $(1.6249)$ & $(0.5734)$ \\
\hline \multirow[t]{2}{*}{ Constant } & $-9.0677^{*}$ & $-5.1774^{*}$ & $-15.0997^{*}$ & $-9.3117 * *$ & $-6.5121^{*}$ & $-5.2743^{*}$ \\
\hline & $(2.7636)$ & $(1.6386)$ & $(3.2433)$ & $(3.8089)$ & $(4.1237)$ & $(1.4636)$ \\
\hline \multirow[t]{2}{*}{ Year $80 / 90$} & -2.0693 & -3.2933 & 4.2757 & 4.6924 & -5.0039 & -2.6649 \\
\hline & $(3.1403)$ & $(2.0717)$ & $(4.3428)$ & $(4.2997)$ & $(4.6108)$ & $(1.6589)$ \\
\hline \multirow[t]{2}{*}{ Year 90} & 3.1103 & 0.3436 & 4.1090 & -0.2863 & 3.6294 & 1.3448 \\
\hline & $(2.3071)$ & $(2.0515)$ & $(4.0584)$ & (3.0838) & $(3.3591)$ & $(1.2181)$ \\
\hline$R^{2}$ & 0.13 & 0.21 & 0.13 & 0.07 & 0.08 & 0.15 \\
\hline
\end{tabular}




\begin{tabular}{|c|c|c|c|c|c|c|}
\hline Test*90 & 0 & 0 & 0.08 & n.s. & 0 & 0 \\
\hline Test*80/90 & 0 & 0 & n.s. & 0.10 & 0 & 0 \\
\hline \multicolumn{7}{|c|}{ Children $6-12$} \\
\hline \multirow[t]{2}{*}{ Income } & $-0.0002^{* *}$ & 0.0001 & & -0.0001 & $-0.0002^{* *}$ & $-0.000^{* *}$ \\
\hline & $(0.0001)$ & $(0.0001)$ & & $(0.0001)$ & $(0.0001)$ & $(0.0001)$ \\
\hline \multirow[t]{2}{*}{ Income $80 / 90$} & 0.0001 & $-0.0003^{*}$ & & $0.0003^{* * *}$ & 0.0001 & $0.0002^{*}$ \\
\hline & $(0.0001)$ & $(0.0001)$ & & $(0.0002)$ & $(0.0001)$ & $(0.0001)$ \\
\hline \multirow[t]{2}{*}{ Income 90} & -0.0001 & 0.0001 & & $-0.0002^{* * *}$ & -0.0001 & $-0.0002^{*}$ \\
\hline & $(0.0001)$ & $(0.0001)$ & & $(0.0001)$ & $(0.0001)$ & $(0.0000)$ \\
\hline \multirow[t]{2}{*}{ Mom's education } & $0.2297^{* * *}$ & $-0.3797^{*}$ & & -0.0347 & 0.1920 & $0.1524^{* * *}$ \\
\hline & $(0.1412)$ & $(0.1265)$ & & $(0.2204)$ & $(0.1352)$ & $(0.0862)$ \\
\hline \multirow{2}{*}{$\begin{array}{l}\text { Mom's education } \\
80 / 90\end{array}$} & $-0.3390^{* * *}$ & 0.2563 & & -0.0549 & $-0.4649^{*}$ & $-0.3596^{*}$ \\
\hline & $(0.1775)$ & $(0.1621)$ & & $(0.2714)$ & $(0.1747)$ & $(0.1066)$ \\
\hline \multirow{2}{*}{$\begin{array}{l}\text { Mom's education } \\
90\end{array}$} & 0.1248 & 0.0956 & & 0.2530 & 0.0473 & $0.2605^{*}$ \\
\hline & $(0.1491)$ & $(0.1429)$ & & $(0.2212)$ & $(0.1627)$ & $(0.0851)$ \\
\hline \multirow[t]{2}{*}{ Mom works } & 1.1963 & 0.6358 & & -1.3299 & $1.6653^{* *}$ & 0.5975 \\
\hline & $(0.8738)$ & $(0.7290)$ & & $(1.2932)$ & $(0.8181)$ & $(0.5195)$ \\
\hline \multirow{2}{*}{$\begin{array}{l}\text { Mom works } 80 / \\
90\end{array}$} & 0.3948 & -0.9409 & & $-2.7658^{* * *}$ & 0.4811 & -0.4439 \\
\hline & $(1.1209)$ & $(0.9660)$ & & $(1.6572)$ & $(1.0945)$ & $(0.6535)$ \\
\hline \multirow[t]{2}{*}{ Mom works 90} & -1.0140 & -0.5357 & & $2.9847^{* * *}$ & -1.0725 & -0.0046 \\
\hline & $(1.0475)$ & $(1.0179)$ & & $(1.5457)$ & $(1.2331)$ & $(0.6018)$ \\
\hline \multirow[t]{2}{*}{ Constant } & $-11.2132^{*}$ & $-5.3732^{*}$ & & $-12.0159^{*}$ & $-10.4250^{*}$ & $-8.1155^{*}$ \\
\hline & $(2.0089)$ & $(1.6519)$ & & $(2.8952)$ & $(1.8770)$ & $(1.1827)$ \\
\hline \multirow[t]{2}{*}{ Year 80/90 } & 1.8186 & -2.4933 & & $10.4299^{*}$ & 4.0610 & 2.2501 \\
\hline & $(2.4867)$ & $(2.2303)$ & & $(3.7284)$ & (2.4806) & $(1.4536)$ \\
\hline \multirow[t]{2}{*}{ Year 90} & 1.2403 & 0.1273 & & -5.2572 & 0.9406 & -1.0017 \\
\hline & (1.8478) & (1.9095) & & $(2.9122)$ & $(2.1776)$ & $(1.0664)$ \\
\hline$R^{2}$ & 0.10 & 0.16 & & 0.09 & 0.17 & 0.14 \\
\hline Test*90 & n.s. & 0.11 & & $\mathrm{n} . \mathrm{s}$ & 0 & 0 \\
\hline Test $* 80 / 90$ & n.s. & 0.03 & & 0.03 & 0.05 & 0.03 \\
\hline
\end{tabular}

Notes: Analyses also include all terms in table 13.6 and their year interactions. "80/90" interactions combine data for 1978-1980 and 1988-1990. "80" interactions combine data for 1978-1980. $p$ value for Test*: likelihood ratio test of joint significance of 1990 and 1980/90 interaction variables. Standard errors in parentheses. n.s. $=$ not significant.

${ }^{*} p<0.01 ;{ }^{* *} p<0.05 ;{ }^{* *} p<0.10$. 
year-olds over time. I find that the presence of older siblings placed younger children at increasing risk between 1968 and 1978, but this result disappears completely by $1988-1990$.

Finally, we examine the hypothesis that regulations aimed at reducing injury in one group led to increased rates of injury in a different group as parents adjusted their behavior to maintain a constant level of safety (e.g., Peltzman 1975). We examine the effect of younger siblings (who are most affected by new regulations) on the mortality of older siblings (six- to twelve-year-olds). The presence of younger siblings never has a substantial or significant positive effect on the mortality of older children (not shown).

In the regressions estimated here, changes in the efficacy of trauma care would be expected to lead to overall reductions in childhood mortality, regardless of changes in family characteristics. In almost all of the cases examined, however, we find no significant change in the regression intercept after 1970 or after 1980 .

Finally, I perform likelihood ratio tests to assess whether the set of interaction coefficients is jointly significant. I test whether the post-1970 coefficients are significant and whether the post- 1980 coefficients are significant. The likelihood ratio tests confirm that the production functions for most causes of death changed significantly between the late 1960s and later and between the late 1970s and late 1980s.

\subsection{The Value of Changes in Child Injury Mortality}

I next estimate the value of the changes measured here. I apply a conservative estimate of $\$ 100,000$ per life year, or about $\$ 3$ million as the value of a life lost from injury to the differences between forecast (extrapolation and prediction) and actual mortality (value of life from Cutler and Richardson 1998). This estimate suggests that the total value of savings for young children amounts to between $\$ 8$ and $\$ 16$ billion each year or $\$ 430$ $\$ 870$ per child per year. The value of total savings for older children amounts to between $\$ 7$ and $\$ 9$ billion each year, or $\$ 280-\$ 360$ per child per year.

\subsection{Discussion}

My analysis suggests that there have been several profound changes in the production of child safety over the past three decades. Formal regulatory interventions, including mandatory car safety seats and fire alarms, can explain relatively little of what has happened. Rather, the results suggest that changes in parents' information about child safety are a more probable cause of the observed declines in mortality. This is not to say that regulations have been unimportant. They are likely to have played an important role in providing information to parents and I find no evidence whatsoever to suggest that they have perverse effects. 
Economic theory suggests that information is usually a public good. One type of information is information about the nature and causes of injury and illness. This type of information is often produced by publicly funded epidemiologists and statisticians who simply examine patterns in the occurrence of events. In many cases, the conclusions of these analyses seem so straightforward that they hardly seem to present new information at all. Yet the history of child safety suggests that identifying quite obvious causes of injury, and ranking their relative importance, is a task that cannot readily be performed by parents. It would not seem necessary to do a study to show that falling out of windows is bad for children, but the New York City experience suggests that without such a study few parents recognize the magnitude of the risk.

Once epidemiological information about the risks of injury and the options for responding to these risks become available, it is disseminated widely (through vehicles such as Dr. Spock and corporations that sell child safety equipment) and consumers appear to act rapidly to make use of this information. The potential of such apparently basic information is important to recognize when assessing the role of technological change in social well-being and the role of government in promoting such technological change.

As information becomes available, it is easier for better educated parents to respond to it. While my results confirm the importance of information in improving child health, they also provide an illustration of how socioeconomic differences in health can be produced through the socially desirable production of valuable information.

\section{References}

Agran, P., D. Castillo, and D. Winn. 1990. Childhood motor vehicle occupant injuries. American Journal of Diseases of Children 144:653-62.

Auster, Richard D., Irving Levenson, and Deborah Sarachek. 1969. The production of health: An exploratory study. Journal of Human Resources 4:41 1-36.

Centers for Disease Control. Division of Injury Control. 1990. Childhood injuries in the United States. American Journal of Diseases of Children 144:627-46.

Consumer Product Safety Commission. 1993. Compilation of statutes administered by Consumer Product Safety Commission. Washington, D.C.: U.S. Government Printing Office.

Cutler, David M., and Elizabeth Richardson. 1998. The value of health: 1970 1990. American Economic Review 88 (2): 97-100.

Grossman, Michael. 1972. On the concept of health capital and the demand for health. Journal of Political Economy 80:223-55.

Johnston, Carden, Fredrick P. Rivara, and Robert Soderbergh. 1994. Children in car crashes: Analysis of data for injury and use of restraints. Pediatrics 93 (6): $360-65$.

Office of Technology Assessment. 1988. Healthy children: Investing in the future. 
Office of Technology Assessment Document no. OTA-H-345. Washington, D.C.: U.S. Government Printing Office.

Peltzman, Sam. 1975. The effects of automobile safety regulation. Journal of Political Economy 83:677-725.

Rivara, Frederick P. 1990. Child pedestrian injuries in the United States. American Journal of Diseases of Children 144:692-96.

Rivara, Frederick P., and David C. Grossman. 1996. Prevention of traumatic deaths to children in the United States: How far have we come and where do we need to go? Pediatrics 97 (6): 791-97.

Robertson, Leon S. 1992. Injury epidemiology. New York: Oxford University Press. Spock, Benjamin. 1957. The common sense book of baby and child care. New ed. New York: Duell, Sloan and Pearce.

1976. Baby and child care. 4th ed. New York: Hawthorn/Dutton.

Spock, Benjamin, and Michael B. Rothanberg. 1992. Dr. Spock's baby and child care. 6th ed. New York: Pocket Books.

U.S. Department of Health and Human Services. Various years. Vital statistics for the U.S. Washington, D.C.: U.S. Government Printing Office.

Wintemute, G. J. 1990. Childhood drowning and near-drowning in the United States. American Journal of Diseases of Children 144:663-69.

\section{Comment James A. Schuttinga}

The paper by Glied is an interesting, unique contribution to this conference volume. It affirms the value of information produced with publicly sponsored research. It illustrates a methodology for evaluating the contribution of epidemiological research to prevention of mortality from childhood injury. And it provides an example of the contribution of research and development (R\&D) to health, when the new information (or technology) is not embodied in a new pharmaceutical, device, or medical procedure. In fact, it demonstrates that $R \& D$ information can substitute for medical care by preventing injury or illness.

As an economist employed by the National Institutes of Health, I am particularly interested in the implications of this paper for two closely related topics--understanding the contribution of medical R\&D to health, and the calculation of a true cost-of-living index.

\section{Review of Findings and Methods}

Something good happened between 1960 and 1990-a 50 percent reduction in mortality rates for children from unintentional injury and an estimated $\$ 15$ billion to $\$ 25$ billion per year in the value of life years saved. Glied specifies a model and examines the effects of several observable variables as possible explanations for the reduction in injury mortality. She

James A. Schuttinga is an economist in the Office of Science Policy, National Institutes of Health. 
attributes the unexplained residual to the effect of epidemiological information on injury prevention. It would be more satisfying to specify a model that includes the instrument of interest and find that the estimated coefficient is statistically significant. That approach does not appear to be an option for this study.

However, Glied is able to tell a credible story. The reduction in injury mortality cannot plausibly be explained by improvements in family resources. Family income did not increase over the period and the share of single mothers and working mothers increased.

She suggests why the epidemiological information was developed. The activities of the Consumer Product Safety Commission stimulated interest in injury epidemiology and well-trained epidemiologists were available. The need for research on infectious diseases was diminishing and injury provided a new opportunity.

The paper provides an explanation of how information is dispensed: through regulations (seatbelts and infant car seats) and threat of product liability, by equipment manufacturers who advertise the benefits of their products, and through guidance books by Dr. Spock and others. It is interesting that a for-profit book was an important instrument for dispensing information.

Glied correctly recognizes that the value and the public goods nature of $\mathrm{R} \& \mathrm{D}$ information justifies public support of certain types of $\mathrm{R} \& \mathrm{D}$, including epidemiological research on causes of injury. We must also recognize the implications of the costliness of producing, disseminating, and using R\&D information and the evolutionary nature of the R\&D process. New information may not be used if people do not know about it or it is deemed too costly. Individuals may find the behavioral changes too onerous or the side effects of a pharmaceutical or other intervention too adverse.

The costliness of using R\&D information on injury has implications for Glied's analysis of the reduction in injury mortality. While she does not dwell on it, the information on injury is costly to use. It requires purchasing and using new safer products at an obvious and identifiable expense. Even more important, it involves behavioral modification. These costs are not usually expressed in market transactions and can be manifest in unanticipated ways. For some activities, like turning pot handles over the stove and using seat belts and infant car seats, the costs are modest. For other behavior modifications, the costs may be more onerous and may be resisted.

I suspect that many childhood activities now deemed risky are simply prohibited without replacement. Slides and jungle gyms, common on school yards in the sixties and earlier, have disappeared today. Children are not allowed to ride bicycles on streets to school, on errands to stores, or simply for recreation. Some of the cost is borne in increased parental chauffeuring. But I suspect that children bear much of the cost in terms 
of a more sedentary, less adventuresome lifestyle. Recent news reports suggest that children spend more time on sedentary activities, particularly video games, and are becoming more obese.

I also suspect that part of the reduction in injury mortality is the side effect of a change in life styles, rather than a conscious choice to avoid risky behavior. The design of suburban communities, the busy two-paycheck families who substitute auto travel and supervised day care for time with children, the slow behavioral adjustment to smaller families, and the fear of child abduction and molestation (rather than fear of injury), all conspire to reduce children's risk exposure as well as their opportunity for exercise and adventure.

For all these reasons, more research on how parents and children respond to the relative costs of alternative behavior modifications is needed. It would be informative to develop a more direct story of the intervention mechanism for information on injury epidemiology (perhaps documented with representative case studies or surveys). How did the parents actually receive the information? How did they modify their behavior? The relative costs of proposed modifications might also explain which behaviors were adopted and which were resisted. The response probably varies by family and person. By analogy, we know that some parents, and prospective parents, are not willing to give up behaviors that put children and fetuses at risk (for illness or injury)-alcohol abuse, smoking, aggressive driving, poor food selection and preparation. The public reaction to the recent revision in obesity guidelines illustrates public distrust of public pronouncements and reluctance to modify pleasurable behavior.

It is not likely that the next 50 percent reduction in injury mortality will result from more epidemiological research on injury alone. Information on which recommendations parents have accepted and what they have resisted is important for designing future interventions.

\section{Implications for Evaluation of the Contributions of Biomedical Research}

Reflection on Glied's paper suggests a number of implications for the evaluation of the contributions of research. She evaluates the contribution of research-generated information that is not embodied in a specific product or device (or, at least, not completely embodied in new, safer products). NIH cannot take much credit for the reduction in mortality rates, because it did not fund most of the underlying epidemiological research on childhood injury. But NIH does fund analogous research that provides information on beneficial behaviors that can improve health and prevent disease. Examples include the "Back to Sleep Program"-placing infants on their backs to sleep to reduce sudden infant death syndrome (SIDS); information on the benefits of folic acid dietary supplementation to prevent neural tube defects; and information on the effect of alcohol abuse on 
health--cirrhosis of the liver and fetal alcohol syndrome. Glied's methods might be useful for evaluating the contribution of this type of information also.

Rather than tracing the impact of a single intervention or piece of information, Glied examines the cumulative impact of a broad class of related interventions--in this case, information on injury prevention. Variations on that approach might be useful to examine the contribution of R\&D to health: when there are multiple, interrelated risk factors (e.g., multiple genetic and behavioral causes of birth defects) or when multiple interventions are available to control a disease or risk factor (e.g., pharmaceuticals and diet to control hypertension) and an intervention can be tailored to the particular needs or preferences of individuals or subpopulations.

I noted that the costliness of using information on injury epidemiology may inhibit use. More generally, the costliness of producing, disseminating, and using $R \& D$ information has implications for the $R \& D$ process and for evaluating the contribution of $R \& D$ for health. Because of public budget constraints, not every project can be funded immediately. As a result, the available information on injury or disease prevention will initially be incomplete. The most effective products/interventions will not be available immediately. The public's lack of knowledge of new information, the less than complete effectiveness of proposed behavioral modifications or interventions, and inconvenience or adverse side effects will all conspire to limit the use and value of R\&D-generated information. Over time, refinements will be developed to improve effectiveness and diminish side effects and costs of use. Partly because public funds will never be sufficient to support all R\&D opportunities or to effectively disseminate all available information, private agents are instrumental in the production, dissemination, and use of R\&D information. Private firms often take the lead in development and refinement of pharmaceuticals or devices that embody the research-generated knowledge. The products or procedures may make it more convenient to use. For example, a pharmaceutical or dietary supplement may deliver the therapeutic benefits without the need for dietary or behavioral adjustments. But private firms may shy away from the process of transforming knowledge developed from basic research into commercial applications if they perceive the process to be too risky or the market too small.

Health care providers, in general, and physicians in particular, are an important intermediary for disseminating R\&D based information. They prescribe pharmaceuticals and procedures and provide information on healthy behavior and risk avoidance. They may be slow to learn about and adopt new procedures and pass on new information when there is not a clear advantage or incentive for them to do so.

A major implication of the costliness is that the benefits of publicly 
funded R\&D-generated information may require years to be completely manifest and will depend on institutional arrangements that influence private agents to develop, disseminate and use $R \& D$ information.

\section{Implications for Cost-of-Living Index}

Glied's analysis of the contribution of information to injury prevention and more general reflection on the evaluation of R\&D contributions suggests a number of implications for the construction of true cost-of-living index for medical care - an index that nets out increased benefits against the increased costs registered by price changes.

First, nonmedical interventions may substitute for medical interventions. The prevention of injury or disease with improved nonmedical products (safer furniture and clothing, smoke alarms, and safety belts) or behavioral modifications can reduce expenditures on medical care. The nonmedical costs and benefits should be netted against changes in medical costs.

Second, the costs of behavioral modifications are not always manifest in prices of market transactions. But such costs should be included in a true cost-of-living index if the associated benefits or reductions in medical expenditures are included.

Third, the costs and benefits of an intervention or a behavioral modification often are not realized during the same period (hospital episode, week, month, or calendar year). As sketched above, because of the evolutionary nature of the $R \& D$ process, the benefits of $R \& D$ information may be fully manifest after several years. A true cost-of-living index must consider the benefits and costs over the complete time horizon.

\section{Final Thoughts}

Glied identified ways that $R \& D$ information contributes to injury prevention (and health improvement generally). It motivates safety regulations, encourages development of new products (partly from threat of lawsuits for defective products), and provides information to parents that enables them to better allocate the resources they devote to child health. I would add another way. R\&D information, especially epidemiological information, generates hypotheses and stimulates new research that contributes to improved information, products, and procedures. I hope that the research reported in this paper will stimulate Glied and others to continue to examine how R\&D information motivates behavioral changes and contributes to improved health. 